\title{
Study of metals contamination in different filter papers
}

\author{
Ibrahim*.O.M. Matoug
}

\begin{abstract}
Membrane filters have come into general use in recent years for the filtration of water samples prior analysis. Membranes are screen filters that remove suspended materials from the water in different size ranges. Filtration is widely accepted as a way of producing acceptable sample and filtration has become a first step in the preparation of water samples for trace metal analysis. Often, the filter is analyzed to study dissolved metal concentration. The investigated show the physical effects of filtration, the most micro fibre filters paper is contaminated by different amount of metal concentrations. On the other hand, there is no metal contamination in the membrane filters nylon.
\end{abstract}

\section{Introduction}

Some research studies have investigated possible contaminants associated with a range of filter types, and the adsorption capacity of filter papers (Dams et al., 1972; Habib and Minski 1981; Jardline et al., 1986; Walsh et al., 1988). Other research studies have been concerned with the physical effects of filtration, and have emphasized differences in trace metal concentrations that are likely to be measured if filters of different pore size are used (Liu et al, 1977; Bertsch, 1989). Berg and Royset 1993, found that, in different brands of filter paper, there are different concentrations of trace metals, for example glass fibre filter had considerable concentrations of metals such as $\mathrm{Cr}$, and $\mathrm{Zn}$. In addition, the quartz filter type showed measurable concentrations of elements including: B, Cr, Mg, Mo, Na, and Zn. Marvin et al. (1970) found that several types of filter paper are contaminated with Cu. Robertson, (1965); Spencer and Manheim, (1969) have determined that the heavy element content of membrane filters used in the filtration process of the water samples is a potential source of contamination.

Some studies have found that some of the factors associated with filtration can considerably change metals concentrations: such as: filter type, filter diameter, filtration method (Horowitz et al,. 1992). Filter paper may be adsorbing some metal from the solution phase or may be releasing metals contamination the solution (Hedberg et al 2011). In the current work, probable contaminants associated with a range of filter paper products were measure to try to develop methods for removing them prior to use. Initially the study entailed a comparison of filter types, using glass micro fibre and nylon membrane of different diameter size $(47,90,125$ $\mathrm{mm})$, of various pore sizes $(1.2 \mu \mathrm{m}$ and $0.2 \mu \mathrm{m})$.

\section{Methods}

A different filter paper is used and analysed to check the amount of metal contamination. Filtration was carried out using Whatman $1.2 \mu \mathrm{m}$ pore size glass micro fibre of different diameter size $(47,125 \mathrm{~mm})$, Whatman $1.2 \mu \mathrm{m}$ pore size micro fibre filters $(47 \mathrm{~mm}$ ) diameter (Acid Treated low Metal), $47 \mathrm{~mm}$ and $90 \mathrm{~mm}$ diameter $0.2 \mu \mathrm{m}$ pore size membrane filters nylon.

Three replicates of filter from the same box were digested in 3:1 hydrochloric acid/nitric acid solution, an aqua regia digest. Filters were analyzed both before and following washing with $5 \mathrm{~L}$ of deionised water. Measurements of metals in the aqua regia digest of $1.2 \mu \mathrm{m}$ and $0.2 \mu \mathrm{m}$ pore size were done by atomic absorption spectrometry (AAS). A metal solution containing solvent only was used as a blank.

\section{Acid treatment of $125 \mathrm{~mm}$ diameter, $1.2 \mu \mathrm{m}$ pore-size micro-fibre filters}

The filter papers were washed by $100 \mathrm{ml}$ of different concentrations of $\mathrm{HNO}_{3}$ passing through the filter paper, to try to remove the contamination of metals in the filter paper. The $125 \mathrm{~mm}$ diameter, $1.2 \mu \mathrm{m}$ pore-size micro-fibre filters were washed using $100 \mathrm{ml}$ of different concentrations of $\mathrm{HNO}_{3}$. The concentrations were 0.1 $\mathrm{M}, 1 \mathrm{M}$ and $5 \mathrm{M} \mathrm{HNO}_{3}$. The acid was filtered through different filter papers, and a different paper was used for each concentration. The filter paper is washing by different concentrations of HNO3 sequentially. This method applies the acid washing to the same filter paper, not like the previous method that applied the washing in different filter paper. $125 \mathrm{~mm}$ diameter, $1.2 \mu \mathrm{m}$ pore-size micro-fibre filters was washed sequentially by different concentration of $\mathrm{HNO}_{3} 0.1 \mathrm{M}, 1 \mathrm{M}$ and $5 \mathrm{M}$. 


\section{Result and discussion}

The results in table (1) indicate filter paper of $47 \mathrm{~mm}$ diameter, $1.2 \mu \mathrm{m}$ pore sizes was contaminated by some metals and that levels of contamination were variable. The metal concentrations decreased after 5 liters deionized water was passed through the filter paper but, even so, the concentration is measurable and unacceptable for use to determine metals concentrations in suspended sediment. There are in fact two features that make the filter paper of $47 \mathrm{~mm}$ diameter, $1.2 \mu \mathrm{m}$ pore-size not appropriate to use to assess metals in the suspended materials. These are the small diameter size, which affects the time of the filtration, and the high concentration of some metals.

Table (1) metal contamination in filter paper $1.2 \mu \mathrm{m}$ pore size microfiber filters (47 and 125$) \mathrm{mm}$

\begin{tabular}{|l|l|l|l|l|c|}
\hline \multirow{2}{*}{ Filter paper size } & \multicolumn{4}{l}{ Concentration $\mathrm{mg} / \mathrm{g}$ Before and after washing } \\
\cline { 3 - 6 } \multicolumn{2}{|l}{} & $\mathrm{Fe}$ & $\mathrm{K}$ & $\mathrm{Na}$ & $\mathrm{Zn}$ \\
\hline $\begin{array}{l}\text { Filter paper } \\
1.2 \mu \mathrm{m}, 47 \mathrm{~mm}\end{array}$ & No washing & $0.147-0.20$ & $4.1-4.7$ & $12-13$ & $5.57-5.76$ \\
\cline { 2 - 6 } & $\begin{array}{l}\text { 5 L deionised } \\
\text { water }\end{array}$ & $0.145-0.20$ & $2.0-2.38$ & $5.1-5.5$ & $2.50-2.60$ \\
\hline $\begin{array}{l}\text { Filter paper1.2 } \\
\mu \mathrm{m}, 125 \mathrm{~mm}\end{array}$ & No washing & $0.075-0.079$ & $3-3.7$ & $12.5-13.3$ & $5.1-5.5$ \\
\cline { 2 - 6 } & 5 L deionised & $0.04-0.043$ & $1.8-2$ & $4.5-5.9$ & $2.4-2.6$ \\
\hline
\end{tabular}

Table (1) shows $125 \mathrm{~mm}$ diameter, $1.2 \mathrm{~mm}$ pore-size microfiber filters measurable concentrations of a number of metals. That before and after filtering through 5 liters deionized water, and after the filter paper has been left in the air to dry. The larger size of diameter of the filter paper makes the filtration process faster, and reduced the filtration time taken. On the other hand, there were high contaminations levels measured in filter papers that make their use not appropriate.

The $125 \mathrm{~mm}$ diameter, $1.2 \mu \mathrm{m}$ pore-size microfiber filters were washed using $100 \mathrm{ml}$ different concentrations of $\mathrm{HNO}_{3}$. The concentrations were $0.1 \mathrm{M}, 1 \mathrm{M}$ and $5 \mathrm{M} \mathrm{HNO}_{3}$. The acid was filtered through different filter papers, and different paper was used for each concentration. Based on the result, there is still an unacceptable contamination in the filter paper. Another method for acidic treatment in the filter paper may be able to help to remove the contaminations in the filter paper digest, washing a filter sequentially with several concentrations of acid.

The filter paper is washing by different concentrations of HNO3 sequentially. In the separately acid washing, some decreased in the metals concentration was measured, comparing with concentration measured after washing by 5 litres deionised water. Even that the concentration was unacceptably in the both ways. There is no different contamination level between $125 \mathrm{~mm}$ and $47 \mathrm{~mm} 1.2 \mu \mathrm{m}$ pore size micro-fibre filters. Application of an acid pre- treatment could possibly remove the contamination from the filters. Therefore this was performed. The most micro fibre filters paper investigation is contamination by different metal concentration, which means this filter paper, is not suitable to determine the mineral deposits in the sediment.

$1.2 \mu \mathrm{m}$ micro fibre filters ( $47 \mathrm{~mm}$ ) (Acid Treated low Metal) had a low concentration of $\mathrm{Zn}$, and Fe are shown in table (2). The concentrations decreased after the 5 litres of water was passed through the filter paper, but there was no marked change in the contamination amount after the washing. In spite of the small diameter of the $1.2 \mu \mathrm{m}$ micro fibre filters $(47 \mathrm{~mm}$ ) (Acid Treated low Metal) that adversely affects the time of the filtration. Hedberg et al 2011 found membrane filtration is not appropriate to determine the dissolved metal fraction. The presence of varying amounts of other metals in the $1.2 \mu \mathrm{m}$ pore-size micro fibre filter apparently cannot be eliminated or reduced. On the other hand, there is no metal contamination in the $47 \mathrm{~mm}$ and $90 \mathrm{~mm}$ diameter 0.2 $\mu \mathrm{m}$ pore size Membrane Filters Nylon. The small diameter size $(47 \mathrm{~mm})$ caused a long filtration time. On the other hand, the large diameter size $(90 \mathrm{~mm})$ causes the filtration time to be shorter.

Table (2) metal contamination in filter paper $1.2 \mu \mathrm{m}$ micro fibre filters $(47 \mathrm{~mm})$ (Acid Treated low Metal)

\begin{tabular}{|l|l|l|l|l|l|l|}
\hline \multirow{2}{*}{$\begin{array}{l}\text { Filter paper1.2 } \\
\mu \mathrm{m}\end{array}$} & \multicolumn{6}{|c|}{ Concentration mg/g } \\
\cline { 2 - 7 } & $\mathrm{Ca}$ & $\mathrm{Fe}$ & $\mathrm{K}$ & $\mathrm{Mg}$ & $\mathrm{Na}$ & $\mathrm{Zn}$ \\
\hline No washing & $2.9-3.1$ & $0.043-0.05$ & $4.1-4.4$ & $1.07-1.11$ & $7.4-7.9$ & $0.011-0.012$ \\
\hline $\begin{array}{l}5 \text { Litres } \\
\text { deionised } \\
\text { water }\end{array}$ & $2.8-3$ & $0.039-0.04$ & $2.9-3.4$ & $0.095-0.99$ & $6.3-7.1$ & $0.010-0.010$ \\
\hline
\end{tabular}




\section{Conclusion}

The investigation of the physical effects of the nomination show the most filter paper employ is contamination by different metals, which means this filter paper is not appropriate to determine metal in the sediment especial micro fibre filters. Because there is some industry contamination in the membrane filters. The filter paper may be can be use to determine trace metal in suspended sediment after subtracting the contaminated concentration, measured in the digested blank filter paper, from the total concentration measured in the digested suspended sediment from the river sample. On the other hand, there is no metal contamination in the membrane filters nylon.

\section{References}

[1]. Berg. T, Royset. O. 1993. Blank value of trace elements in aerosol filters determined by ICP-MS. Atmospheric. Environment, 27, 12435-2439.

[2]. Bertsch P. 1989. Aluminum speciation: methodology and applications. In Advances in Environmental Science. Acidic Precipitatwn (Edited by Adriano D. and Salomons W.), 4, 63-105. Springer, New York. Bruland K. 1983. Trace elements in seawater.

[3]. Dams R., Rahn K., Winchester J. 1972. Evaluation of filter materials and impaction surfaces for nondestructive neutron activation analysis of aerosols. Environmental. Sciences. Technology. 6, 441-448.

[4]. Habib. S., Minski. M. 1981. Neutron activation techniques for the analysis of soluble and particulate fractions of river waters. Journal. Radio-analytical. Chemistry. 63, 379-395.

[5]. Hedberg. Y, Herting. G, Wallinder. I. O, 2011. Risks of using membrane filtration for trace metal analysis and assessing the dissolved metal fraction of aqueous media, A study on zinc, copper and nickel,. Environmental Pollution 159, $1144,1150$.

[6]. Horowitz. A, Elrick. K, Colberg. R. 1992. The effect of membrane filtration artefacts on dissolved trace element concentrations. Water. Resources. 26, 6, 753-763.

[7]. Jardine. P., Zelazny. L. and Evans A. Jr. 1986. Solution aluminum anomalies resulting from various filtering materials. Soil Science. Society of America Journal 50, 891-894.

[8]. Liu S., Carney C. and Hurwitz A. 1977. Adsorption as a possible limitation in solubility determination. J. Pharm. Pharmac. 29, 319321 .

[9]. Marvin K. T., Proctor R. R. and Neal R. A. 1970. Some effects of filtration on the determination of copper in fresh water and salt water. Limnol. Oceanogr. 15, 320-325.

[10]. Robertson D. E. 1965. The role of contamination in trace metal analysis of sea water. Analytical chemistry. 40, 1067-1072.

[11]. Spencer D. W., Mannheim F. T. 1969. Ash content and composition of Millipore HA filters. U.S. Geological Survey Professional Paper 650, 288-290.

[12]. Walsh. M, Knapp L, Jenkins T. 1988. Evaluation of disposable membrane filters units for sorptive losses and sample contamination. Ent, Air. Technology. Lett. 9, 45-52. 